\title{
Mouth protection in sport in Scotland a review
}

C. Holmes 1

\begin{abstract}
The oral health strategy for Scotland, which was published in 1995, recommends that dentists promote the use of mouth protection in sport to reduce the risk of injury. ${ }^{1}$ There is compulsory mouthguard use in some sports including ice-hockey, fencing, boxing, lacrosse and some forms of autocycling. In cricket, face protection appears to be compulsory for batsmen only. The use of mouth protection in the martial arts is compulsory at international level but, in the UK, the rule does not seem to be always enforced at club level. Players of contact sports, such as rugby and hockey, are considered to be more at risk of dentoalveolar injury and the governing bodies of these sports recommend that players at all levels wear mouth protection but have not made it mandatory.
\end{abstract}

\begin{abstract}
$T^{t}$ is difficult to ascertain the number of dentoalveolar injuries sustained as a result of a sporting injury, but some people are more at risk. In the 1960s it was estimated that participants in contact sports had a $10 \%$ chance of oral injury each season $^{2}$ with a $33-56 \%$ chance of oral injury at some point in their playing lifetime. ${ }^{3} \mathrm{~A}$ more recent study of 14 to 15 - year-old Sheffield school children showed that $26 \%$ of oral injuries were a result of participation in sport. ${ }^{4}$

In some sports, such as cycling, horseriding and skateboarding, the younger age group are most at risk of dental injury because they are learning, but in team sports the highest risk is in young adults aged 20-30 because they play more frequently. The risk of injury also increases with higher levels of competition when players are more committed and probably have more exposure. The risk in cricket is highest in 40-49-year-olds, which is a reflection of the age at which people play cricket and, perhaps, on the slowing of reactions in older players. ${ }^{5}$
\end{abstract}

\footnotetext{
${ }^{1}$ Catherine Holmes, Centre for Dental Education, University of Edinburgh, Postgraduate Dental Institute, Level 4 Lauriston Building, Lauriston Place, Edinburgh EN3 9YW REFEREED PAPER

Received 17.09.99; Accepted 23.12.99

(c) British Dental Journal 2000; 188: 473-474
}

There does not appear to be much awareness of or much interest in the need for mouth protection among sports players in Scotland. The author carried out an unpublished postal survey of 33 governing bodies of sports in Scotland. There was no
In brief
- Although mouthguards are compulsory in some sports and are often worn by rugby and hockey players, people participating in sport are not generally aware of the need for mouth protection.
- Custom made mouthguards offer better protection than the 'boil to bite' type but many people do not have them because they are expensive and necessitate a visit to the dentist.
- The oral health strategy for Scotland recommends that dentists promote the use of mouth protection in sport but there is no NHS fee for making a mouthguard and so children and exempt groups have to pay a private fee. This does not encourage the use of mouthguards.
- Any oral health promotion project to promote the use of mouth protection should be targeted at governing bodies, coaches and schools as well as players but should also include funding for custom made mouthguards to be provided under the NHS. This might also encourage dentists to provide mouthguards for patients who participate in any sport.

response from 18 of them. Those responsible for motor sport, tennis, baton twirling and volleyball did not consider mouth protection to be relevant to their sports. The governing bodies of women's football, football, hockey, rugby, roller hockey, basketball and horseriding said that they were interested in learning more about mouth protection but did not respond to an offer of a presentation on the topic. There is more interest in mouth protection among players of rugby and hockey, where mouthguards are worn by professional players, who may be see as role models.

\section{Which mouthguard?}

There is much evidence to suggest that professionally fitted custom made mouthguards are the best type. ${ }^{6-8}$ 'Boil and bite' mouthguards can be bought in sports shops and self fitted by placing in hot water and biting into the softened lining. Studies published in the dental and the sporting literature have found that 'boil and bite' mouthguards provide inadequate protection and some authors have gone as far as recommending that this type of mouthguard be banned from use in sport. ${ }^{9-11}$ 'Boil and bite' mouthguards can be bought for $£ 2-3$, but custom made mouthguards involve at least one, and possibly two, visits to a dentist and cost anything from $£ 20$ upwards. In addition, the recommendations of several studies are that sports players should have a new mouthguard annually or every two years, depending on use, and that children should renew their mouthguards annually because of growth changes in the mouth and jaws. ${ }^{12-16}$ The cost implications of these recommendations are not inconsiderable. There is no NHS fee for a dentist to make a mouthguard for patients who are exempt from NHS charges. The parents of sports playing children have to pay a private fee for custom made mouthguards, even if their dentist treats them under the NHS. This is also true for people who are on state benefits. These people are more likely to use a $£ 2$ 'boil and bite' mouthguard, if they use any mouth protection at all. People may think that they should be registered with a 
dentist before they can ask to have a mouthguard made. The community dental service will provide free custom-made mouthguards for their own patients in some Health Board areas and, in other areas, GDPs can refer children to the CDS to have a mouthguard made free of charge. For most children and adults in Scotland who play sport the choice remains: either they wear no mouth protection, or they buy a cheap mouthguard from a sports shop which provides inadequate protection and might be dangerous, or they visit a dentist (and this may be problematic) to be provided with a custom-made mouthguard for which they have to pay.

\section{Barriers to use}

Apart from cost, other barriers to mouthguard use include problems with retention, speech, nausea, dryness and difficulty in breathing, ${ }^{17}$ although there is better compliance for custom-made mouthguards than the 'boil and bite' variety. ${ }^{15}$ Previous orofacial injury sustained while playing rugby does not appear to be a major factor in the decision to wear mouth protection among rugby players. ${ }^{16}$ Girls and lower social groups appear to be less likely to wear mouth protection. ${ }^{4}$ Australian amateur football players reported that the primary reasons for not wearing a mouthguard were 'too much hassle' and 'never thought of it.' 6 Student athletes revealed that they preferred custom-made mouthguards to self adapted types but the cost and the inconvenience of having to make a dental appointment to obtain a custom-made one was a major drawback. ${ }^{17}$

The two dental schools in Scotland do not train undergraduates to provide sport specific mouth protection and this topic has never been covered by any postgraduate training in Scotland. Anecdotal evidence has revealed that dentists do not, on the whole, know which type of mouth protection is most suitable for each sport and what oral structures should be included in impressions for a mouthguard. Dental technicians appear to be more knowledgeable. This is probably

\section{Clubs should be encouraged to appoint an honorary dentist whose job would be to ensure that all members have adequate and suitable mouth protection for their level of play.}

because mouthguards are covered by the personal protective equipment legislation of 1995 and themanufacturer must comply with the legislation. ${ }^{18}$

\section{Future action}

If the recommendations of the oral health strategy for Scotland are to be taken forward, a health promotion programme is necessary. Members of the dental team should be encouraged never to let pass an opportunity for promoting mouth protection in sport. This should include raising awareness about the need for mouth protection for participants in sports where mouthguard use is not traditional. Scotland's favourite sport of football is an obvious example. Advocacy for mouthguard use should also focus on coaches, coaches' organisations and governing bodies. For those sports where mouth protection is more usual, players should be encouraged to wear custom-made mouthguards and renew them at least every two years. Coaches and teachers should be encouraged to insist on players wearing mouthguards for training as well as matches. Mouthguard use by children should be encouraged for all sports in schools and clubs. There should be a NHS fee for dentists in general dental practice to provide mouth protection for children and exempt groups. Dentists may need training in order to fulfil this role. The use of mouthguards by professional sports people, particularly footballers, would set an example. Despite the best efforts of the author to encourage Scottish footballers to wear a mouth guard none has so far proved willing to do so.

1 The Oral Health Strategy for Scotland Edinburgh HMSO 1995

2 Moon DG and Mitchell DF. An evaluation of a commercial protective mouthpiece for football players. J Am Dent Assoc 1961; 62: 568-572.

3 Clegg JH. Mouth protection for the Rugby football player. Br Dent J 1969; 127: 341-343

4 Rodd HD and Chesham DJ Sports related oral injury and mouthguard use among Sheffield schoolchildren. Community Dent Health 1997; 14: 25-30.

5 Hill CM, Crosher RF and Mason DM. Dental and facial injuries following sports accidents: a study of 130 patients. Br J Oral Maxillofac Surg. 1985; 23: 268-274.

6 Jolly KA et al. The promotion of mouthguards among amateur football players in Victoria. Aust and NZ J Public Health 1996; 20: 630-639.

7 Jennings DC. Injuries sustained by users and non-users of gum shields in local rugby union. Br J Sports Med 1987; 24: 159-165.

8 Chapman PJ. Orofacial injuries and the use of mouthguards by the 1984 GB rugby league touring team. Br J Sports Med 1985; 19: 3436.

9 Chalmers DJ. Mouthguards - protection for the mouth in Rugby Union Sports Med 1998; 25: 339-349

10 Turner CH. Mouth protectors $1977 \mathrm{Br}$ Dent J;143: 82-86

11 Greasley A, Imlach G, Karet B. Application of a standard test to the in vitro performance of mouthguards. Br J Sports Med 1998; 32: 17-19

12 Park JB et al. Improving mouthguards J Prosthet Dent 1994; 72: 373-80 .

13 Natt PJ. Custom made mouthguards for contact sports players. Personal Communication.

14 Dorney B. Mouthguard protection in sports injury Case report Aust Dent J 1994; 39: 378.

15 Chapman PJ. Players' attitudes to mouthguards and prevalence of orofacial injuries in the 1987 US rugby football team Am J Sports Med 1989; 17: 690-691.

16 McCarthy MF Sports and mouth protection Gen Dent 1990; 38: 343-346.

17 Ranalli DN and Lancaster DM Attitudes of college football coaches regarding NCAA mouthguard regulations and player compliance J Public Health Dent 1995; 55: 139-142

18 Natt EM. Instructions for the manufacture of Sportsguard mouthguards. 1996. Malchpen House, 45-47 Friern Barnet Road, London N11 3EP 